\title{
The Relationship between an Accessory Maxillary Ostium and Variations in Structures Adjacent to the Maxillary Sinus without Polyps
}

\author{
Gozde Serindere $^{1 \oplus}$ Kaan Gunduz ${ }^{2}$ Hakan Avsever $^{3}$ \\ ${ }^{1}$ Department of Dentomaxillofacial Radiology, Faculty of Dentistry, \\ Hatay Mustafa Kemal University, Hatay, Turkey. \\ 2 Department of Dentomaxillofacial Radiology, Faculty of Dentistry, \\ Ondokuz Mayıs University, Samsun, Turkey. \\ ${ }^{3}$ Department of Dentomaxillofacial Radiology, Gulhane Faculty of \\ Dentistry, Health Sciences University, Ankara, Turkey. \\ Int Arch Otorhinolaryngol 2022;26(4):e548-e555.
}

Address for correspondence Gozde Serındere, associate professor, Department of Dentomaxillofacial Radiology, Faculty of Dentistry, Hatay Mustafa Kemal University, 31060 Hatay, Turkey (e-mail: gozdeserindere@mku.edu.tr).

\begin{abstract}
Introduction The maxillary sinus and its variations are very important to dentistry and rhinology.

Objective To investigate the effect of the accessory maxillary ostium (AMO) on the variations of adjacent structures of the maxillary sinus.

Methods The computed tomography (CT) images of 400 patients were retrospectively evaluated. The prevalence of AMO was calculated. The relationship between morphological variations of adjacent structures of maxillary sinus such as agger nasi cell (ANC), Haller cell (HC), nasal septum deviation (NSD), hypertrophy of inferior concha (HIC), pneumatization of middle concha (PMC), mucus retention cyst (MRC), mucosal thickening (MT), and maxillary sinusitis (MS), as well as the presence of AMO, were investigated.

Results Presence of AMO was diagnosed in 42 patients (10.5\%), having been found in $4.5 \%$ of the patients only on the right side, in $1.25 \%$ of the patients only on the left side,

Keywords

- computed tomography

- paranasal sinuses

- sinus anatomy

- sinusitis and in $4.75 \%$ of the patients on both sides. There is an increasing incidence of ANC, HC, NSD, HIC, and PMC in the presence of AMO and MS. There is a decreasing incidence of MRC in the presence of AMO. Furthermore, AMO does not affect the incidence of MT. Conclusion This study showed that most parameters, except for MRC and MT, had increasing incidence in the presence of AMO. It is important for radiologists and rhinologists to have knowledge about the location of AMO and the presence of variations of MS adjacent structures to avoid surgical complications.
\end{abstract}

\section{Introduction}

The natural ostium of the maxillary sinus is anteriorly placed and has a transversely oval form. It is not visible with nasal

received

May 18, 2021

accepted after revision

October 17, 2021

published online

January 28, 2022
DOI https://doi.org/ 10.1055/s-0042-1742325. ISSN 1809-9777. endoscopic evaluation. ${ }^{1}$ The ostium of the maxillary sinus is at the highest part of the medial wall of the sinus and is, therefore, poorly placed in terms of free drainage; in addition, it does not open into the nasal fossa, but into the narrow

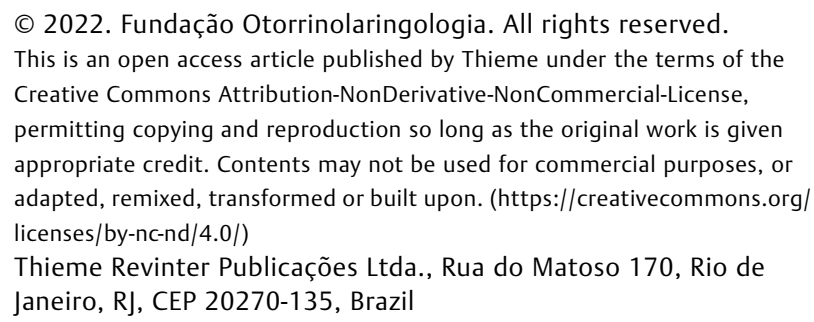

(C) 2022. Fundação Otorrinolaringologia. All rights reserved. This is an open access article published by Thieme under the terms of the Creative Commons Attribution-NonDerivative-NonCommercial-License, permitting copying and reproduction so long as the original work is given appropriate credit. Contents may not be used for commercial purposes, or adapted, remixed, transformed or built upon. (https://creativecommons.org/ licenses/by-nc-nd/4.0/) Thieme Revinter Publicações Ltda., Rua do Matoso 170, Rio de Janeiro, RJ, CEP 20270-135, Brazil 
ethmoidal infundibulum, and its inflammation may further inhibit drainage. ${ }^{2}$

In addition to a natural ostium connecting the maxillary sinus to the middle meatus, endoscopic in vivo evaluations commonly reveal the presence of an accessory maxillary ostium (AMO) in the maxillary fontanelle. ${ }^{3}$ The AMO is generally situated on the posterior fontanelle of the lateral nasal wall. The maxillary hiatus should not be confused with AMO. ${ }^{1}$ An AMO is observed in $30 \%$ of patients suffering from chronic maxillary sinusitis (MS) and in 10 to $20 \%$ of healthy individuals. ${ }^{4,5}$

Chronic sinusitis causes significant morbidity despite appropriate medical and surgical treatment. Anatomical variations, including AMO, play a role in the pathogenesis of chronic MS. An AMO impairs mucociliary clearance of the maxillary sinus owing to the recycling of mucus between the natural and accessory ostia, and this process may result in chronic MS. ${ }^{6}$ It is not clear whether an AMO is congenital or acquired. Some authors claim that it may develop after acute MS. ${ }^{7}$

The aim of this study was to evaluate the incidence of AMO and the relationship between an AMO and variations in structures adjacent to the maxillary sinus.

\section{Materials and Methods}

The present study is a retrospective study, approved by the Local Ethics Committee of the Faculty of Medicine of the Hatay Mustafa Kemal University (decision date: 26/12/2019, decision number: 07). The medical history of all patients was noted through the picture archiving and communication system (PACS) of the university hospital. The computed tomography (CT) scans of 400 patients (male $=222$, female $=178$ ) who had been referred to the Department of Dentomaxillofacial Radiology of our University Hospital were evaluated.

The exclusion criteria from this study were:

- Patients with maxillofacial trauma.

- Patients undergoing sinus surgery.

- Patients diagnosed with nasal polyps, acute sinusitis, inverted papilloma, choanal atresia, or advanced nasal septal deviation (NSD) contacting the lateral nasal wall.

- CT scans with low-quality images.

The study of Yenigun et al. ${ }^{8}$ investigated the prevalence of AMO and the relationship between an AMO and anatomical variations in the adjacent anatomical structures, namely the agger nasi cell (ANC), Haller cells (HC), NSD, pneumatisation of the middle turbinate or concha (concha bullosa; PMC), hypertrophy of the inferior concha (HIC), maxillary sinusitis (MS), mucus retention cysts (MRC), and mucosal thickening (MT) ( - Figs. 1,2,3,4,5). The following definitions were taken into account in the evaluation of the parameters:

ANC: Agger nasi cells are frontal ethmoidal cells, located in front of the anterior end of the middle concha and uncinate process in the nasal lateral wall. ${ }^{9}$

HC: Haller cells are alternatively referred to as infraorbital ethmoid cells, as they arise from anterior ethmoid cells and are located in the medial orbital floor. ${ }^{10}$

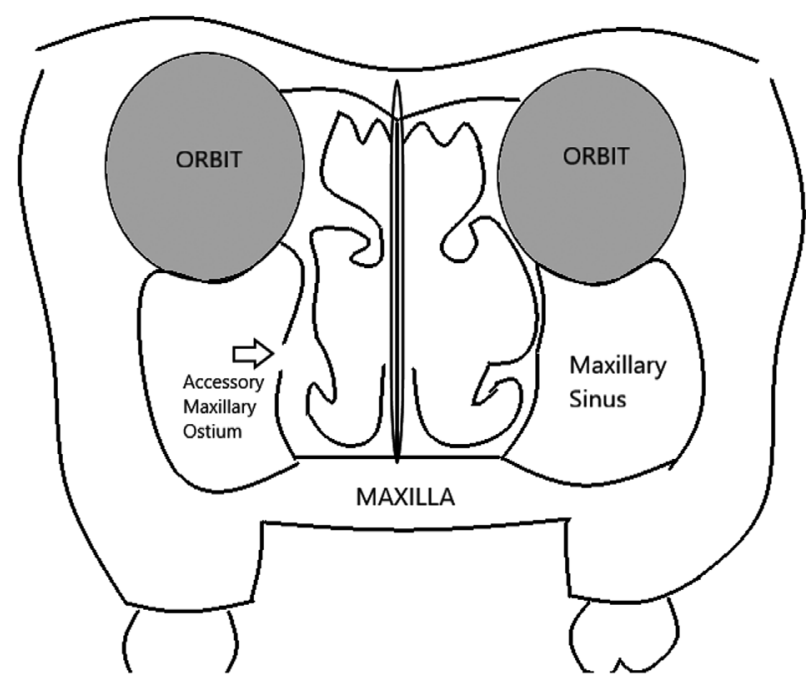

Fig. 1 Schematic diagram of the accessory maxillary ostium.

NSD: Nasal septal deviation is a common condition in which the bone or cartilage of the nasal septum is deviated from the midline of the face. ${ }^{11}$

PMC: Pneumatization of the middle turbinate, or concha, is caused by an air-filled cavity in a concha or turbinate. ${ }^{12}$ HIC: Hypertrophy of the inferior concha is a condition encountered with NSD, caused by the increase in the size of the inferior concha (also called compensatory hypertrophy of the inferior concha). The hypertrophy is observed on the opposite side to the NSD. For example, if the nasal septum deviates to the right, the hypertrophy is observed to the left. ${ }^{13}$

MS: Inflammation of the maxillary sinuses. The symptoms of sinusitis are headache, generally in the region of the non-healthy sinus, and possibly a foul-smelling nasal or pharyngeal discharge, sometimes combined with systemic infection such as fever and malaise. The skin over the non-healthy sinus may be tender, hot or even reddened because of inflammation. In radiological examination, opacification (or clouding) of the translucent sinus is generally observed because of mucus involvement. ${ }^{14}$

MRC: According to the study of Bhattacharyya, ${ }^{15}$ a diagnosis of MRC is based on the following criteria:

- a homogeneous, dome-shaped cyst with sharp borders;

- a lack of bony destruction;

- a lack of communication with tooth roots;

- a smooth, spherical contour along the cyst-free border.

MT: Mucosal thickening often coexists with chronic MS, ${ }^{16}$ and is probably pathological when larger than $2 \mathrm{~mm}$. However, even MT up to 4 to $5 \mathrm{~mm}$ can be asymptomatic and go unnoticed by the patient. ${ }^{17}$

A Toshiba Aquilion (Canon Medical Systems Corp. Ōtawara, Tochigi, Japan) CT scanner was used for all the maxillofacial CT procedures. A routine maxillofacial CT protocol was conducted. All evaluations were performed with a Lenovo IdeaPad 520 notebook (Lenovo Ltda. Hong Kong, 


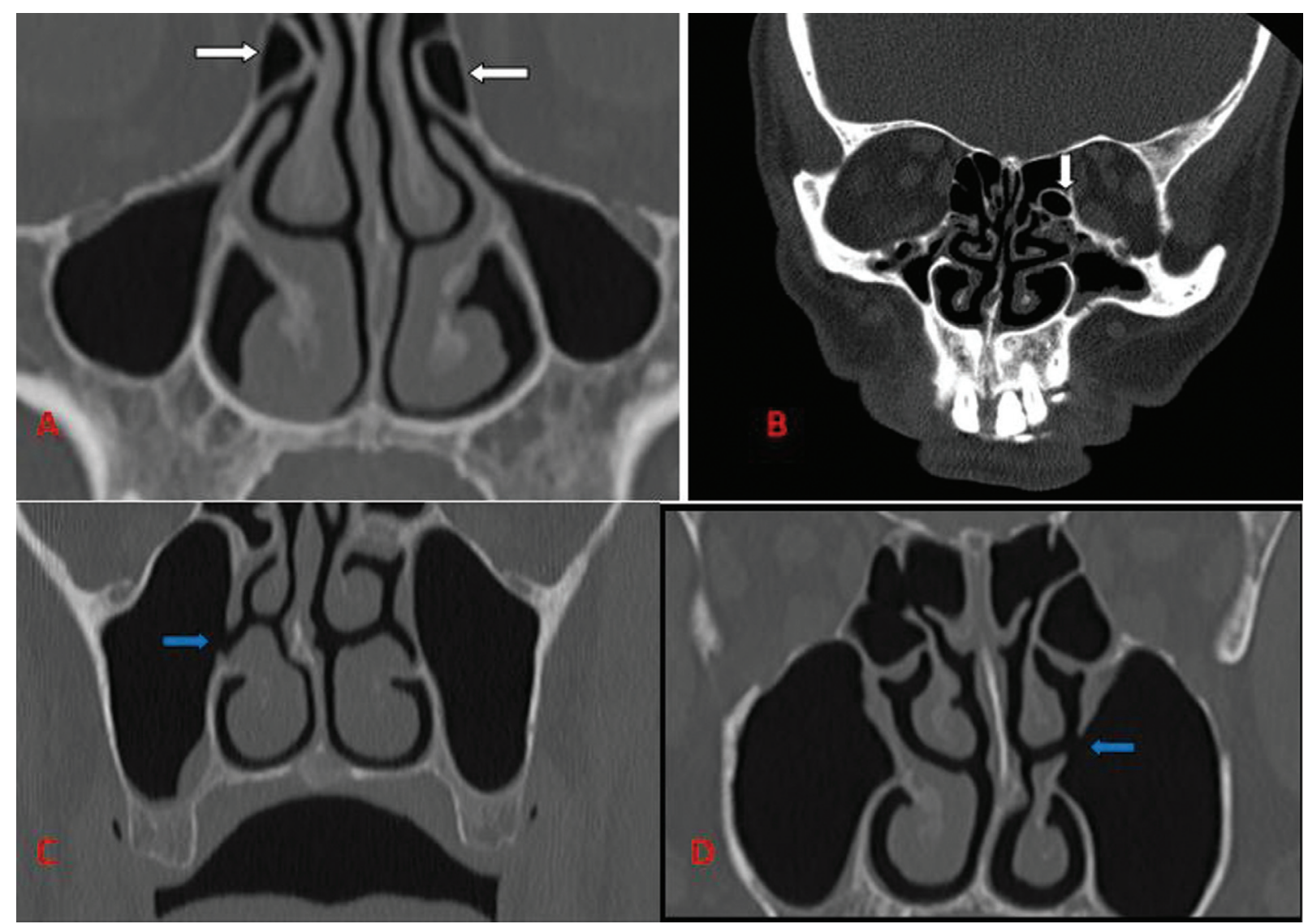

Fig. 2 Agger nasi cell (A and B - white arrows) and accessory maxillary ostium (C and D - blue arrows).

China) with 15.6 -inch and $1920 \times 1080$ resolution. All evaluations were done by a single blinded observer, Gozde Serindere, who had 6 years of clinical experience. In case there was any disagreement, these were solved by consensus with Professor Kaan Gunduz, who had nearly 15 years of clinical experience.

During the evaluations, the data of each patient were recorded in an Excel table (Microsoft Co. Redmond, Washington, USA). The Statistical Package Social Sciences (SPSS, StataCorp LLC. College Station, Texas, USA) software, version 16 , was used to describe and analyze the data. The data were also analyzed by odds ratio (OR), in such way that the OR was obtained for the presence or absence of an AMO, as compared with the presence or absence of each of the potential complications. The significance level was set at $p=0.05$.

\section{Results}

Of the 400 patients included in the study, 222 were male (55.5\%) and 178 were female (44.5\%). The patients' ages were between 7 and 87 years, and their mean age was of $40.7 \pm 18.3$ years.

\section{The Incidence of AMO}

In this study, the presence of an AMO and accompanying morphological variations in neighboring structures were assessed in 800 sides of 400 patients. We diagnosed 42

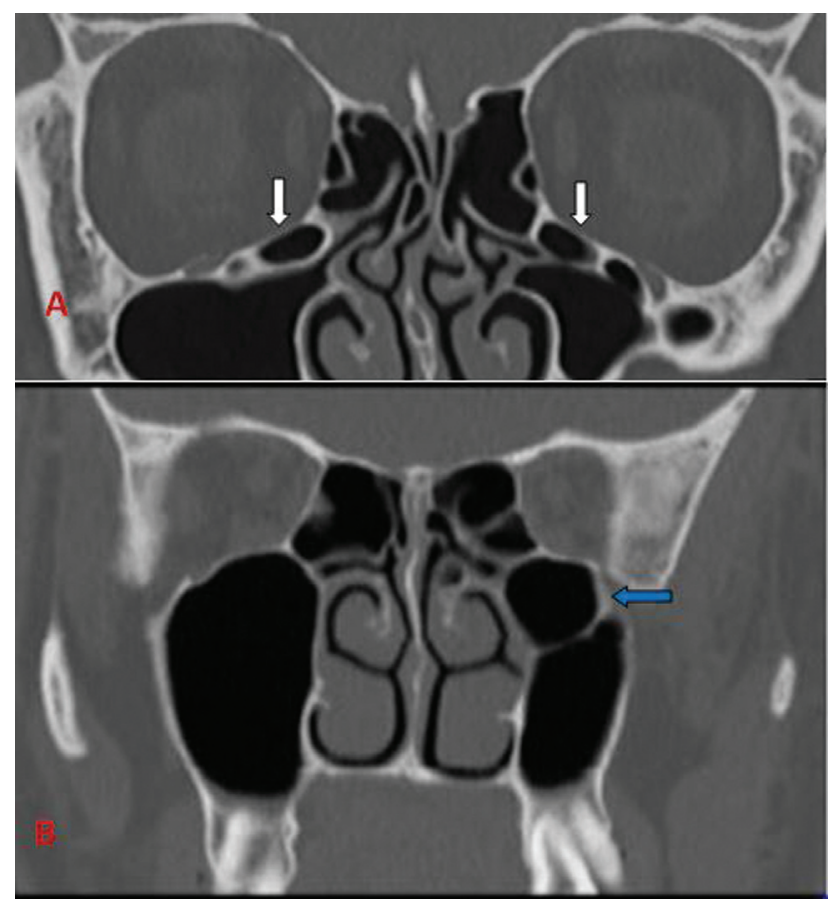

Fig. 3 A - Haller cell (white arrows); B - Big Haller cell (blue arrow).

patients (10.5\%) with AMO, having been found in $4.5 \%$ of the patients on the right side, in $1.25 \%$ of the patients on the left side, and bilaterally in $4.75 \%$ of the patients. 

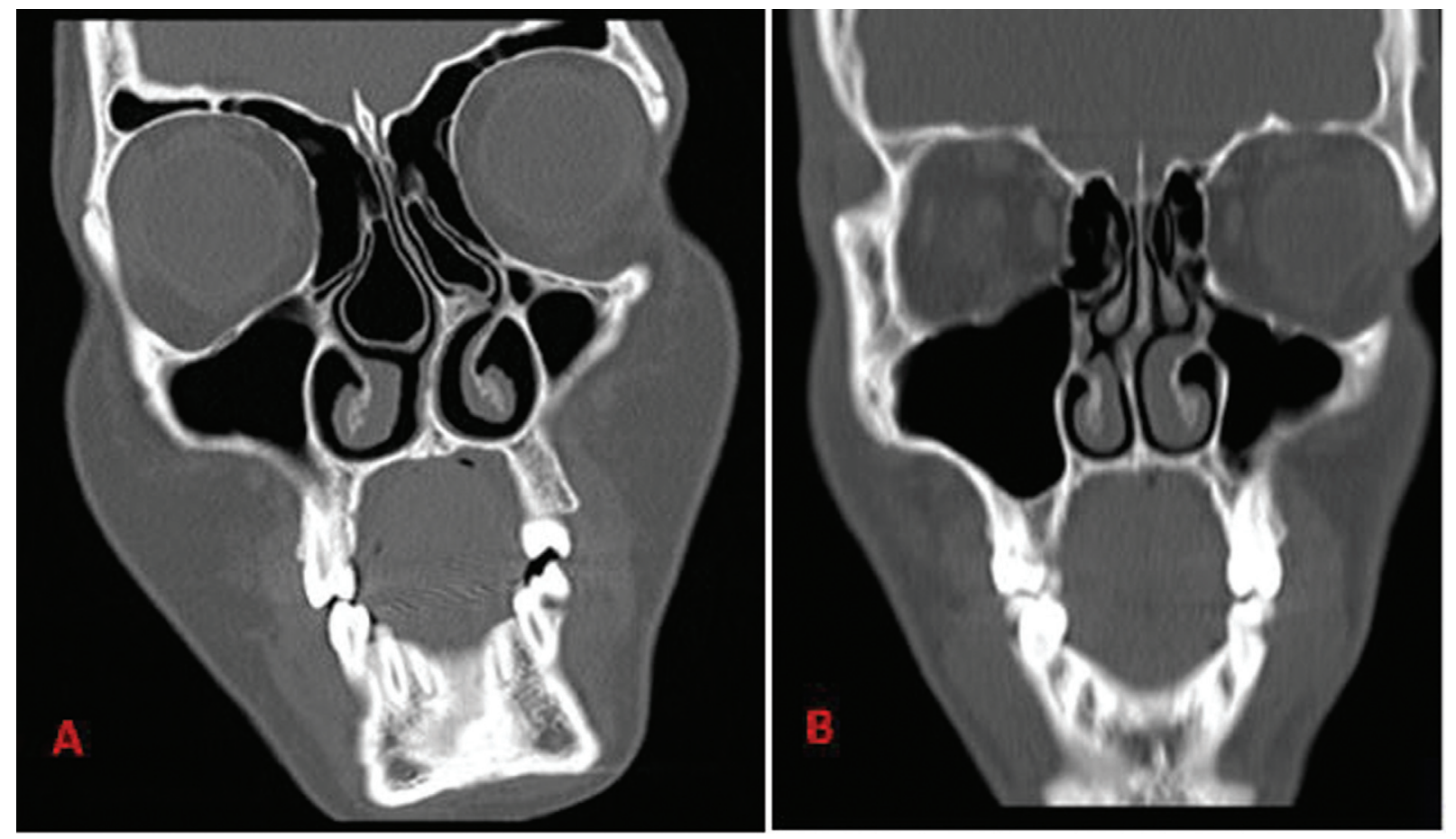

Fig. 4 A - Bilateral pneumatization of middle concha and left nasal septum deviation B - Right nasal septum deviation with left hypertrophy of inferior concha.

\section{The Relationship between AMO and ANC}

We identified ANC in $49.3 \%$ of the studied subjects. In $31 \%$ $(26 / 84)$ of the cases, ANC was diagnosed along with an AMO, 28.6\% of which (12/42) the AMO was on the right side, $2.4 \%(1 / 42)$ it was on the left side, and $15.5 \%$ (13/84) where it was bilateral. Among the 716 sides in 358 patients without an AMO, ANC was found in $2.2 \%(16 / 716)$ of the cases, with $1.7 \%(6 / 358)$ on the right side, $1.1 \%(4 / 358)$ on the left side, and $0.8 \%(6 / 716)$ bilateral. The incidence of ANC increased by $77 \%$ in the presence of an AMO (OR $=1.77)($-Table $\mathbf{1})$.

\section{The Relationship between AMO and HC}

We identified HC in $10.3 \%$ of the studied subjects. In $5.9 \%$ (5/84) of the cases, it was found along with an AMO, 2.4\% $(1 / 42)$ of which the AMO was on the right side, and $4.7 \%$ (4/84) where it was bilateral. In patients without an AMO, HC was found in $5.16 \%(37 / 716)$, with $4.75 \%(17 / 358)$ on the right side, $1.4 \%(5 / 358)$ on the left side, and bilaterally in $2.1 \%$ (15/716). The incidence of HC increased by $20 \%$ in the presence of an AMO $(\mathrm{OR}=1.20)(-$ Table $\mathbf{1})$.

\section{The Relationship between AMO and NSD}

We identified NSD in $41.5 \%$ of the studied subjects. In $23.8 \%$ (20/84) of the cases, it was found along with an AMO, 23.8\% (10/42) of which it was on the right side, and $11.9 \%(10 / 84)$ it was bilateral. In patients without an AMO, NSD was found in $3.07 \%(22 / 716)$ of the cases, with $2.2 \%(8 / 358)$ on the right side, $1.4 \%(5 / 358)$ on the left side, and $1.25 \%$ (9/716) bilateral. The incidence of NSD increased by $32 \%$ in the presence of an AMO $(\mathrm{OR}=1.32)($ - Table $\mathbf{1})$.

\section{The Relationship between AMO and HIC}

We identified HIC in $35 \%$ of the studied subjects. It was found in $22.6 \%(19 / 84)$ of the cases with an AMO, with $23.8 \%$ (10/42) being on the right side and $10.7 \%$ (9/84) bilateral. In patients without an AMO, HIC was found in 3.2\% (23/716) of the cases, with $2.2 \%$ ( $8 / 358$ ) on the right side, $1.4 \%(5 / 358)$ on the left side, and $1.4 \%(10 / 716)$ bilateral. The incidence of HIC increased by $61 \%$ in the presence of an AMO $(\mathrm{OR}=1.61)$ (-Table 1).

\section{The Relationship between AMO and PMC}

We identified PMC in $14.5 \%$ of the studied subjects. It was found in $8.3 \%(7 / 84)$ of the cases with an AMO, with $11.9 \%$ (5/42) being on the right side, and 2.9\% (2/84) bilateral. In patients without AMO, PMC was found in $4.9 \%$ (35/716) of the cases, with $3.6 \%(13 / 358)$ on the right side, $1.4 \%(5 / 358)$ on the left side, and $2.4 \%$ (17/716) bilateral. The incidence of PMC increased by $20 \%$ in the presence of an AMO $(\mathrm{OR}=1.20)$ (-Table 1).

\section{The Relationship between AMO and MRC}

We identified MRC in $8.5 \%$ of the studied subjects. In 2.4\%(2/84) of the cases, MRC was found along with an AMO. It was found in 5.6\% (40/716) of the cases without an AMO, with 4.75\% (17/358) being on the right side, $1.4 \%(5 / 358)$ on the left side, and $2.5 \%$ (18/716) bilateral. The incidence of MRC decreased by $50 \%$ in the presence of an $\mathrm{AMO}(\mathrm{OR}=0.50)(-$ Table $\mathbf{1})$.

\section{The Relationship between AMO and MS}

We identified MS in $49.8 \%$ of the studied subjects. It was found in $28.6 \%(24 / 84)$ of the cases with an AMO, $23.8 \%$ 

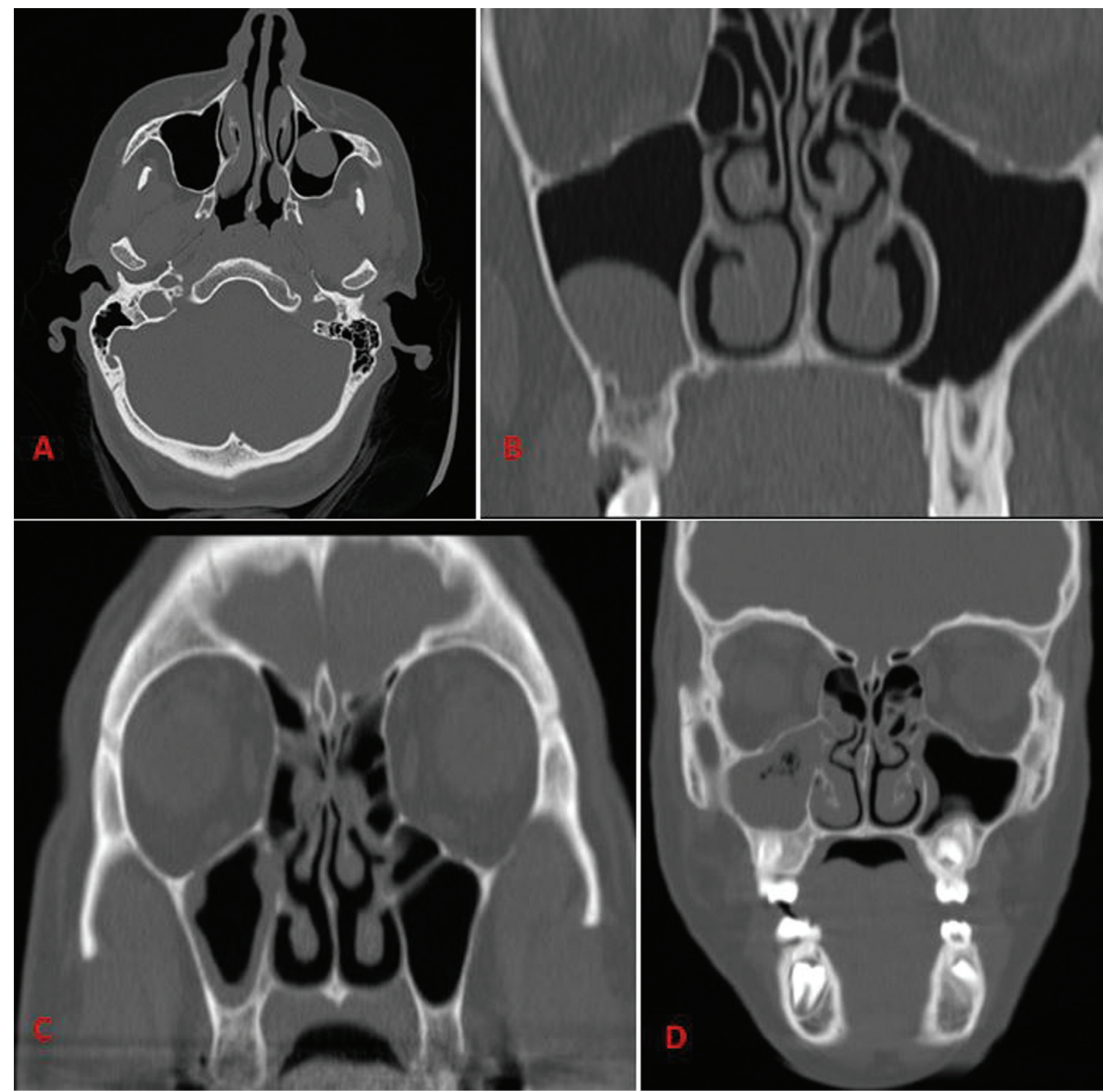

Fig. 5 Axial (A) and Coronal (B) scans of mucus retention cyst. C -mucosal thickening in right side; D -maxillary sinusitis.

(10/42) of which were on the right side, $7.1 \%(3 / 42)$ on the left side, and $13.1 \%(11 / 84)$ bilateral. In patients without an AMO, MS was found in $2.5 \%$ (18/716) of the cases, with $2.2 \%$ (8/358) being on the right side, $0.5 \%(2 / 358)$ on the left side, and $1.1 \%(8 / 716)$ bilateral. The incidence of MS increased by $39 \%$ in the presence of an AMO $(\mathrm{OR}=1.39)$ ( - Table $\mathbf{1})$.

\section{The Relationship between AMO and MT}

We diagnosed $24 \%$ of the studied subjects with MT. It was found in $11.9 \%$ (10/84) of the cases with an AMO, 14.3\% (6/42) of which were on the right side and 4.7\% (4/84) bilateral. In patients without an AMO, MT was found in 4.5\% (32/716) of the cases, with $3.3 \%(12 / 358)$ being on the right side, $1.4 \%$ (5/358) on the left side and 2.1\% (15/716) bilateral. Therefore, AMO did not increase nor decrease MT $(\mathrm{OR}=0.98)$ (-Table 1).

\section{Discussion}

Although the literature contains several studies of the incidence of AMO, to the best of our knowledge, only one other article $^{8}$ discusses the presence of an AMO and anatomical variations in adjacent structures and sinus diseases. Thus, the present study aimed to investigate the relationship between the incidence of AMO and the many important variations in adjacent structures, along with the presence of sinusitis. In studies performed with cadavers and patients, the reported prevalence of AMO was in the range of 0 to $43 \%{ }^{18,19}$ It was reported as $10 \%$ by May et al., $2015 \%$ by Kennedy and Zinteich, ${ }^{21} 18.5 \%$ by Singhal and Singhal, ${ }^{22}$ $19.1 \%$ by Yenigun et al., ${ }^{8} 23 \%$ by Van Alyea, ${ }^{23}$ and $43 \%$ by Schaeffer. ${ }^{24}$ However, some of the current studies have shown results above this range. Yeung et al. ${ }^{25}$ and Hung 
Table 1 Concurrence of accessory maxillary ostium with neighboring morphologic variants

\begin{tabular}{|c|c|c|c|c|c|}
\hline Variations & $\begin{array}{l}\text { Presence/absence } \\
\text { of right AMO N (\%) }\end{array}$ & $\begin{array}{l}\text { Presence/absence } \\
\text { of left AMO N (\%) }\end{array}$ & $\begin{array}{l}\text { Presence/absence } \\
\text { of bilateral AMO N (\%) }\end{array}$ & $\begin{array}{l}\text { Presence/absence } \\
\text { of total AMO N (\%) }\end{array}$ & OR \\
\hline Agger nasi cell & $12-6(28.6-1.7)$ & $1-4(2.4-1.1)$ & $13-6(15.5-0.8)$ & $26-16(31-2.2)$ & 1.77 \\
\hline Haller cell & $1-17(2.4-4.75)$ & $0-5(0-1.4)$ & $4-15(4.7-2.1)$ & $5-37(5.9-5.16)$ & 1.20 \\
\hline $\begin{array}{l}\text { Nasal septum } \\
\text { deviation }\end{array}$ & $10-8(23.8-2.2)$ & $0-5(0-1.4)$ & $10-9(11.9-1.25)$ & $20-22(23.8-3.07)$ & 1.32 \\
\hline $\begin{array}{l}\text { Hypertrophy of in- } \\
\text { ferior concha }\end{array}$ & $10-8(23.8-2.2)$ & $0-5(0-1.4)$ & $9-10(10.7-1.4)$ & $19-23(22.6-3.2)$ & 1.61 \\
\hline $\begin{array}{l}\text { Pneumatization of } \\
\text { middle concha }\end{array}$ & $5-13(11.9-3.6)$ & $0-5(0-1.4)$ & $2-17(2.9-2.4)$ & $7-35(8.3-4.9)$ & 1.20 \\
\hline $\begin{array}{l}\text { Mucus retention } \\
\text { cysts }\end{array}$ & $1-17(2.4-4.75)$ & $0-5(0-1.4)$ & $1-18(1.2-2.5)$ & $2-40(2.4-5.6)$ & 0.50 \\
\hline Maxillary sinusitis & $10-8(23.8-2.2)$ & $3-2(7.1-0.5)$ & $11-8(13.1-1.1)$ & $24-18(28.6-2.5)$ & 1.39 \\
\hline $\begin{array}{l}\text { Mucosal } \\
\text { thickening }\end{array}$ & $6-12(14.3-3.3)$ & $0-5(0-1.4)$ & $4-15(4.7-2.1)$ & $10-32(11.9-4.5)$ & 0.98 \\
\hline
\end{tabular}

Abbreviations: AMO, accessory maxillary ostium; OR, odds ratio.

Note: In patients with AMO, the first number in the table represents the number of patients with corresponding left column variation, and the second number represents the number of patients without variation.

et al. $^{26}$ reported the incidence of AMO as $45.5 \%$ and $47.2 \%$, respectively. In the present study, the incidence (10.5\%) was found to be slightly lower, although within the range reported in previous studies.

Avsever et al. ${ }^{27}$ reported the incidence of ANC, HC, NSD and PMC as $2.9 \%, 3.2 \%, 13.2 \%$ and $13.7 \%$, respectively. The present study found higher results. Arslan et al. ${ }^{28}$ reported the incidence of AMO, MRC and NSD as 30\%, 18.2\% and 58.7\%, respectively. The parameters reported in our study were shown to be lower. In the study of Yenigun et al., ${ }^{8}$ the incidence of right, left, and bilateral AMO was $7.2 \%, 3.7 \%$, and $8.2 \%$, respectively. Kumar et al. ${ }^{18}$ reported that AMO incidence was twice as high on the right side compared with the left. Similarly, in the present study, an AMO incidence was found in $4.5 \%$ of the patients on the right side, in $1.25 \%$ of the patients on the left side, and in $4.75 \%$ of the patients bilaterally.

The incidence of ANC was reported as $51.9 \%$ by Özdemir et al., ${ }^{29} 40 \%$ by Orhan and Saylam, ${ }^{30} 62.8 \%$ by Yenigun et al. ${ }^{8}$ and $81.8 \%$ by Liu et al. ${ }^{31}$ In the present study, ANC was diagnosed in $49.3 \%$ of the studied subjects. In $31 \%$ of the cases, it was diagnosed in the presence of AMO, with a $77 \%$ increase. By contrast, Yenigun et al. ${ }^{8}$ reported that there was no statistical significance in the simultaneous presence of AMO and ANC.

The incidence of $\mathrm{HC}$ has been reported to vary from 2 to $45 \%$ in the literature. ${ }^{32}$ In the present study, the incidence was found to be $10.5 \%$, which places it within the reported limits. In $5.9 \%$ of the cases, it was found along with AMO, with a $20 \%$ increase. By contrast, Yenigun et $a .^{8}$ reported that there was no statistical significance for the simultaneous presence of AMO and HC.

Some studies have reported NSD in from 20 to $31 \%$ of the community, and also found that severe deviation predisposed the population to rhinosinusitis. ${ }^{33-35}$ In Turkey, some studies reported the incidence of NSD as $39 \%{ }^{36}$ in adults and
$34.9 \%{ }^{37}$ in children. Yenigun et al. ${ }^{8}$ reported the incidence of NSD as $47.7 \%$. In present study, the incidence was $41.5 \%$, similar to other studies in the literature. However, in the studies by de Oliveira et al., ${ }^{38}$ Stallman et al. ${ }^{39}$ and Clark et al., ${ }^{40}$ a higher incidence $(60.3 \%, 65 \%$ and $76 \%$, respectively) was reported. In our study, NSD was found along with AMO in $23.8 \%$ of the cases. In contrast to the present study, Yenigun et $a .^{8}$ reported that there was no statistical significance for the simultaneous presence of AMO and NSD.

The incidence of HIC was reported as $37.4 \%$ by Yenigun et al., ${ }^{8} 72 \%$ by Clark et al. ${ }^{40}$ and $6.83 \%$ by Cury et al. ${ }^{41}$ The present study found that HIC was diagnosed in $35 \%$ of the studied subjects, with $22.6 \%$ being diagnosed along with AMO. The low incidence in the study of Cury et al. ${ }^{41}$ may be due to the use of panoramic radiography as the radiological method. Yenigun et al. $^{8}$ reported that the simultaneous presence of AMO and HIC was statistically significant on the left side but not significant on the right side. In this study, there was a $61 \%$ increasing incidence of HIC in the presence of AMO.

The incidence of PMC was reported in the range between 13 and $72.2 \%$ in the literature. ${ }^{42-44}$ Stallman et al. ${ }^{39}$ and Yenigun et al. ${ }^{8}$ reported the incidence of PMC as $44 \%$ and $44.9 \%$, respectively. In the present study, PMC was diagnosed in $14.5 \%$ of the studied subjects, $8.3 \%$ of whom were also diagnosed with AMO, with an increase of $20 \%$. By contrast, Yenigun et al. $^{8}$ reported that there was no statistical significance for the simultaneous presence of AMO and PMC.

The diagnosis of MRC in the maxillary sinus is frequent, and radiological studies reported its incidence as 9 to $22 \%$ in the general population, similar to our findings of $8.5 \%{ }^{45}$ Yenigun et al. $^{8}$ reported that the presence of AMO was associated with an approximate 3-fold increase in the incidence of MRC. However, in this study, a 50\% decreasing incidence of MRC in the presence of AMO was reported.

The incidence of MT was found to be $25 \%$ by Yenigun et al., ${ }^{8} 38.1 \%$ by Ritter et al., ${ }^{46} 35.1 \%$ by Raghav et al., ${ }^{47} 21.25 \%$ 
by Drumond et al., ${ }^{48}$ and $25.1 \%$ by Gracco et al. ${ }^{49}$ Compatible with these studies, our study indicated that MT was diagnosed in $24 \%$ of the studied subjects, and in $14.3 \%$ it was found along with AMO. MT is formed in paranasal sinuses after infection out of maxillary sinuses, whereas the development of MRC is very rarely seen. ${ }^{50,51}$ In the present study, the incidence of MT was found to be higher than that of MRC, possibly for the same reason. Yenigun et al. ${ }^{8}$ reported that the presence of AMO was associated with a nearly 2-fold increase in the incidence of MT. By contrast, in our study, the presence of AMO did not increase nor decrease incidence of MT.

The most frequent disease of the paranasal sinuses is MS, and theincidence of odontogenic MS ranges from 10 to $40 \%$ of all MS. ${ }^{52}$ Drumond et al. ${ }^{48}$ found the lower incidence of chronic sinusitis and chronic odontogenic sinusitis to be $7.48 \%$ and $2.29 \%$, respectively. Yenigun et al. ${ }^{8}$ reported the incidence of MS as $14.5 \%$. A higher incidence of $49.8 \%$ was found in our study, $28.6 \%$ of which it was diagnosed along with AMO. Yenigun et al. ${ }^{8}$ reported that the presence of AMO was associated with a nearly 2-fold increase in the incidence of MS. Bani-Ata et al. ${ }^{53}$ reported that the presence of AMO can contribute to the occurrence of MS. Similarly, in our study, a $39 \%$ increasing incidence of MS in the presence of AMO was observed.

The differences in results may be due to the large number of parameters in our study, their effects on one another, and therefore the extensive literature review involving evaluation of studies conducted in different populations, using different numbers of patients and different radiological modalities.

Vital structures such as the skull base, optic nerves, internal carotid arteries, and orbits lie near the paranasal sinuses. Some anatomic variants increase the risk of injury in these structures, and a clear understanding of the patient's individual paranasal sinus anatomy obtained by CT examination is very important for safe endoscopic sinus surgery. ${ }^{54}$ In most cases, CT is accepted as a gold standard modality to diagnose the sinus diseases, as multiple contiguous thin sections in axial, sagittal and coronal planes can be obtained. Bone and soft tissue observation can also be performed. ${ }^{55}$

It should also be noted that MS can have life-threatening complications, such as orbital, intracranial, or combinations thereof. Intracranial complications of sinusitis are diseases that require an emergency approach, early diagnosis, and intensive treatment. ${ }^{56,57}$

\section{Conclusion}

This study involved sinus diseases without polyps. The results showed that the incidence of all parameters, except for MRC and MT, increased in the presence of AMO. Thus, in cases with AMO, it is vital that the clinician be aware of maxillary sinus variations to avoid complications during maxillary sinus surgery. Although the literature contains several studies on the anatomy and variations in the maxillary sinus, the present study is, to the best of our knowledge, one of the most detailed studies of the presence of AMO and anatomical variations in adjacent structures, and their rela- tion to sinus diseases. Hence, we believe that our study will be a guide for future research.

Conflict of Interests

The authors have no conflict of interests to declare.

\section{References}

1 Stammberger H. Functional endoscopic sinus surgery. The Messerklinger technique.Philadelphia: BC Decker1990;247:63-7

2 Hollinshed WH, Rosse C. Text book of Anatomy. $4^{\text {th }}$ edn. Herper and RowPhiladelphia1985:976-85

3 Na Y, Kim K, Kim SK, Chung SK. The quantitative effect of an accessory ostium on ventilation of the maxillary sinus. Respir Physiol Neurobiol 2012;181(01):62-73. Doi: 10.1016/j. resp.2012.01.013

4 Joe JK, Ho SY, Yanagisawa E. Documentation of variations in sinonasal anatomy by intraoperative nasal endoscopy. Laryngoscope 2000;110(2 Pt 1):229-235. Doi: 10.1097/00005537200002010-00008

5 Jones NS. CT of the paranasal sinuses: a review of the correlation with clinical, surgical and histopathological findings. Clin Otolaryngol Allied Sci 2002;27(01):11-17. Doi: 10.1046/j.03077772.2001.00525.x

6 Matthews BL, Burke AJ. Recirculation of mucus via accessory ostia causing chronic maxillary sinus disease. Otolaryngol Head Neck Surg 1997;117(04):422-423. Doi: 10.1016/S0194-5998(97)70139-6

7 Parsons DS, Wald ER. Otitis media and sinusitis: similar diseases. Otolaryngol Clin North Am 1996;29(01):11-25

8 Yenigun A, Fazliogullari Z, Gun C, Uysal II, Nayman A, Karabulut AK. The effect of the presence of the accessory maxillary ostium on the maxillary sinus. Eur Arch Otorhinolaryngol 2016;273(12): 4315-4319. Doi: 10.1007/s00405-016-4129-8

9 Yegin Y, Çelik M, Şimşek BM, Olgun B, Canpolat S, Kayhan FT. Relationship Between the Presence of Agger Nasi Cells and the Development of Frontal Sinusitis: a Computer-Assisted Anatomic Study. Bezmialem Science 2017;5:112-115. Doi: 10.14235/ bs.2017.1087

10 Mathew R, Omami G, Hand A, Fellows D, Lurie A. Cone beam CT analysis of Haller cells: prevalence and clinical significance. Dentomaxillofac Radiol 2013;42(09):20130055. Doi: 10.1259/ dmfr.20130055

11 Vig KW. Nasal obstruction and facial growth: the strength of evidence for clinical assumptions. Am J Orthod Dentofacial Orthop 1998;113(06):603-611. Doi: 10.1016/s0889-5406(98) 70219-7

12 Hatipoğlu HG, Cetin MA, Yüksel E. Concha bullosa types: their relationship with sinusitis, ostiomeatal and frontal recess disease. Diagn Interv Radiol 2005;11(03):145-149

13 Chiesa Estomba C, Rivera Schmitz T, Ossa Echeverri CC, Betances Reinoso FA, Osorio Velasquez A, Santidrian Hidalgo C. Compensatory hypertrophy of the contralateral inferior turbinate in patients with unilateral nasal septal deviation. A computed tomography study. Otolaryngol Pol 2015;69(02):14-20. Doi: 10.5604/00306657.1149568

14 Fehrenbach MJ, Herring SW. Illustrated Anatomy of the Head and Neck. Elsevier Health Sciences; 2012 page 67

15 Bhattacharyya N. Do maxillary sinus retention cysts reflect obstructive sinus phenomena? Arch Otolaryngol Head Neck Surg 2000;126 (11):1369-1371. Doi: 10.1001/archotol.126.11.1369

16 Kolo ES. The role of plain radiographs in the diagnosis of chronic maxillary rhinosinusitis in adults. Afr Health Sci 2012;12(04): 459-463. Doi: 10.4314/ahs.v12i4.10

17 Ren S, Zhao H, Liu J, Wang Q, Pan Y. Significance of maxillary sinus mucosal thickening in patients with periodontal disease. Int Dent J 2015;65(06):303-310. Doi: 10.1111/idj.12186 
18 Kumar H, Choudhry R, Kakar S. Accessory Maxillary Ostia: Topography and Clinical Application. J Anat Soc India 2001;50 (01):3-5

19 Jog M, McGarry GW. How frequent are accessory sinus ostia? J Laryngol Otol 2003;117(04):270-272. Doi: 10.1258/ 00222150360600869

20 May M, Sobol SM, Korzec K. The location of the maxillary os and its importance to the endoscopic sinus surgeon. Laryngoscope 1990;100 (10 Pt 1):1037-1042. Doi: 10.1288/00005537-199010000-00002

21 Kennedy DW, Zinteich J. Otolaryngology, Head and Neck, Vol III. W.B. Saunders Company; 1991:1861-71

22 Singhal MD, Singhal DM. Anatomy of accessory maxillary sinus ostium with clinical application. Int J Med Sci Public Health 2014; 3:327-329. Doi: 10.5455/ijmsph.2013.301220131

23 Van Alyea OE. The Ostium Maxillare anatomic study of its surgical accessibility. Arch Otolaryngol 1936;24(05):553-569

24 Schaeffer JP. The Nose, Paranasal Sinuses, Nasolacrimal Passageways, and Olfactory Organ in Man. Philadelphia: P. Blakiston's Son; 1920

25 Yeung AWK, Colsoul N, Montalvao C, Hung K, Jacobs R, Bornstein MM. Visibility, location, and morphology of the primary maxillary sinus ostium and presence of accessory ostia: a retrospective analysis using cone beam computed tomography (CBCT). Clin Oral Investig 2019;23 (11):3977-3986. Doi: 10.1007/s00784-019-02829-9

26 Hung K, Montalvao C, Yeung AWK, Li G, Bornstein MM. Frequency, location, and morphology of accessory maxillary sinus ostia: a retrospective study using cone beam computed tomography (CBCT). Surg Radiol Anat 2020;42(02):219-228. Doi: 10.1007/ s00276-019-02308-6

27 Avsever H, Gunduz K, Karakoç O, Akyol M, Orhan K. Incidental findings on cone-beam computed tomographic images: paranasal sinus findings and nasal septum variations. Oral Radiol 2018;34 (01):40-48. Doi: 10.1007/s11282-017-0283-y

28 Arslan İB, Uluyol S, Demirhan E, Kozcu SH, Pekçevik Y, Çukurova İ Paranasal Sinus Anatomic Variations Accompanying Maxillary Sinus Retention Cysts: A Radiological Analysis. Turk Arch Otorhinolaryngol 2017;55(04):162-165. Doi: 10.5152/ tao.2017.2759

29 Özdemir A, Arslan S. Incidence of agger nasi and frontal cells and their relation to frontal sinusitis in a Turkish population: a CT study. Anatomy 2018;12(02):71-75. Doi: 10.2399/ana.18.050

30 Orhan M, Saylam CY. Anatomical analysis of the prevalence of agger nasi cell in the Turkish population. Kulak Burun Bogaz Ihtis Derg 2009;19(02):82-86

31 Liu SC, Wang $\mathrm{CH}$, Wang HW. Prevalence of the uncinate process, agger nasi cell and their relationship in a Taiwanese population. Rhinology 2010;48(02):239-244. Doi: 10.4193/Rhin09.118

32 Stackpole SA, Edelstein DR. The anatomic relevance of the Haller cell in sinusitis. Am J Rhinol 1997;11(03):219-223. Doi: $10.2500 / 105065897781751910$

33 Shin HS. Clinical significance of unilateral sinusitis. J Korean Med Sci 1986;1(01):69-74. Doi: 10.3346/jkms.1986.1.1.69

34 Lebowitz RA, Brunner E, Jacobs JB. The agger nasi cell: radiological evaluation and endoscopic management in chronic frontal sinusitis. Operative techniques. Otolaryngol Head Neck Surg 1995;6:171-175

35 Wanamaker HH. Role of Haller's cell in headache and sinus disease: a case report. Otolaryngol Head Neck Surg 1996;114 (02):324-327. Doi: 10.1016/s0194-5998(96)70196-1

36 Özkırış M, Mutlu C. Kulak burun boğaz polikliniğine başvuran hastalarda nazal septum deviasyonu sıklığı. J Kartal TR 2010;XXI (02):72-76

37 Yildirim I, Okur E. The prevalence of nasal septal deviation in children from Kahramanmaras, Turkey. Int J Pediatr Otorhinolaryngol 2003;67(11):1203-1206. Doi: 10.1016/j.ijporl.2003.07.005

38 Oliveira AKP, Elias E Jr, Santos LV, Bettega SG, Mocellin M. Prevalence of deviated nasal septum in Curitiba, Brasil. Int Arch Otorhinolaryngol 2005;9(04):288-292
39 Stallman JS, Lobo JN, Som PM. The incidence of concha bullosa and its relationship to nasal septal deviation and paranasal sinus disease. AJNR Am J Neuroradiol 2004;25(09):1613-1618

40 Clark DW, Del Signore AG, Raithatha R, Senior BA. Nasal airway obstruction: Prevalence and anatomic contributors. Ear Nose Throat J 2018;97(06):173-176. Doi: 10.1177/014556131809700615

41 Cury R, Gioseffi C, Andrade E, Cury M, Cury SE. The incidence of inferior turbinate hypertrophy in a Brazilian population. Webmed central. Rhinology 2013;4(06):WMC004276

42 Aktas D, Kalcioglu MT, Kutlu R, Ozturan O, Oncel S. The relationship between the concha bullosa, nasal septal deviation and sinusitis. Rhinology 2003;41(02):103-106

43 Arslan H, Aydinlioğlu A, Bozkurt M, Egeli E. Anatomic variations of the paranasal sinuses: CT examination for endoscopic sinus surgery. Auris Nasus Larynx 1999;26(01):39-48. Doi: 10.1016/ s0385-8146(98)00024-8

44 Bolger WE, Butzin CA, Parsons DS. Paranasal sinus bony anatomic variations and mucosal abnormalities: $\mathrm{CT}$ analysis for endoscopic sinus surgery. Laryngoscope 1991;101(1 Pt 1):56-64. Doi: 10.1288/00005537-199101000-00010

45 Albu S. Symptomatic maxillary sinus retention cysts: should they be removed? Laryngoscope 2010;120(09):1904-1909. Doi: 10.1002/lary.21040

46 Ritter L, Lutz J, Neugebauer J, et al. Prevalence of pathologic findings in the maxillary sinus in cone-beam computerized tomography. Oral Surg Oral Med Oral Pathol Oral Radiol Endod 2011;111(05):634-640. Doi: 10.1016/j.tripleo.2010.12.007

47 Raghav M, Karjodkar FR, Sontakke S, Sansare K. Prevalence of incidental maxillary sinus pathologies in dental patients on conebeam computed tomographic images. Contemp Clin Dent 2014;5 (03):361-365. Doi: 10.4103/0976-237X.137949

48 Drumond JPN, Allegro BB, Novo NF, de Miranda SL, Sendyk WR. Evaluation of the prevalence of maxillary sinuses abnormalities through spiral computed tomography (CT). Int Arch Otorhinolaryngol 2017;21(02):126-133. Doi: 10.1055/s-0036-1593834

49 Gracco A, Incerti Parenti S, Ioele C, Alessandri Bonetti G, Stellini E. Prevalence of incidental maxillary sinus findings in Italian orthodontic patients: a retrospective cone-beam computed tomography study. Korean J Orthod 2012;42(06):329-334. Doi: 10.4041/ kjod.2012.42.6.329

50 Wang JH, Jang YJ, Lee BJ. Natural course of retention cysts of the maxillary sinus: long-term follow-up results. Laryngoscope 2007;117(02):341-344

51 Hong SL, Cho KS, Roh HJ. Maxillary sinus retention cysts protruding into the inferior meatus. Clin Exp Otorhinolaryngol 2014;7 (03):226-228. Doi: 10.3342/ceo.2014.7.3.226

52 Mehra P, Murad H. Maxillary sinus disease of odontogenic origin. Otolaryngol Clin North Am 2004;37(02):347-364. Doi: 10.1016/ S0030-6665(03)00171-3

53 Bani-Ata M, Aleshawi A, Khatatbeh A, et al. Accessory maxillary ostia: prevalence of an anatomical variant and association with chronic sinusitis. Int J Gen Med 2020;13:163-168. Doi: 10.2147| IJGM.S253569

54 Nouraei SA, Elisay AR, Dimarco A, et al. Variations in paranasal sinus anatomy: implications for the pathophysiology of chronic rhinosinusitis and safety of endoscopic sinus surgery. J Otolaryngol Head Neck Surg 2009;38(01):32-37

55 Campbell PD Jr, Zinreich SJR, Aygun N. Imaging of the paranasal sinuses and in-office CT. Otolaryngol Clin North Am 2009;42(05): 753-764, vii

56 Clayman GL, Adams GL, Paugh DR, Koopmann CF Jr. Intracranial complications of paranasal sinusitis: a combined institutional review. Laryngoscope 1991;101(03):234-239. Doi: 10.1288/00005537199103000-00003

57 Giannoni C, Sulek M, Friedman EM. Intracranial complications of sinusitis: a pediatric series. Am J Rhinol 1998;12(03):173-178. Doi: $10.2500 / 105065898781390127$ 